\title{
On guilt and the depoliticization of downsizing practices
}

\begin{abstract}
Purpose - The purpose of this paper is to provide a theoretical conceptualisation of guilt and the depoliticization of downsizing practices. We begin with a critical review of the relevant management literature aiming to establish the discursive normalization and individualization of (un)employment. We then use secondary sources to reflect on the downsizing process. A process that, as we argue, is distinguished into three separate but interconnected phases: corporate memos (phase 1), termination scripts (phase 2), and the role of outplacement services (phase 3). By examining this process our aim is to point to the mechanisms through which downsizing practices are neutralized and depoliticized.

Design/methodology/approach - This is a conceptual work that provides a systematic overview of the existing management literature on downsizing and guilt. Use of other secondary sources (corporate memos and termination scripts) are also employed to draw links between the discursive normalisation of downsizing as identified in the relevant literature and the specific organisational processes and practices implemented by corporations during downsizing. We identify common ideas and themes that cut across the relevant literature and the secondary sources and aim to offer a theoretical conceptualisation of guilt and the depoliticization of downsizing practices.

Findings - This paper argues that downsizing discourses and practices contribute to feelings of personal responsibility and self-blame, reinforcing an individualistic understanding of work and unemployment that excludes more structural ones, and that it helps in reproducing the existing structures of power.

Research limitations/implications - Our study recognises that employees' reactions are not only unpredictable but also constantly evolving, depending on personal and social circumstances. We also recognise that our work is based on secondary sources much of which talk about practices in US companies, and thus we are and should be cautious of generalisations. We hope however that we will encourage further empirical research, particularly among organization studies and critical management scholars, on downsizing practices and guilt. For our part, we have tried to offer a critical reflection on how guilt is produced through corporate discourses and practices, and we believe that further empirical investigation on the three phases of the downsizing process (as identified in our work) and the lived experience of (un)employment is needed. As corporate downsizing discourses and practices frame (un)employment in strictly individualist and behavioural terms, we wish to emphasize the need for further theoretical investigation and political contestation. We therefore hope that our work will contribute to the relevant literature on downsizing practices and open up the discussions around layoff policies and the structural conditions of (un)employment.

Originality/value - The paper shows that downsizing practices and feelings of guilt are strongly linked to and exemplify the 'individualization' of social and political issues such as work and unemployment. We suggest that individualization signifies, in some sense, a retreat from organized collective resistance and mobilization based upon class and that the prevalence of the ideology of individualism (and its correlative, meritocracy), over alternative explanations and solutions to such public issues, helps in reproducing existing structures of power and inequity.
\end{abstract}

Keywords: Guilt, Downsizing, Individualization, Unemployment 


\section{Introduction}

There can be little doubt that in western culture the notion of guilt has been profoundly important, at least within the Judeo-Christian tradition. Diverse and often cognate disciplines and bodies of thought such as the historical study of Christianity (Delumeau, 1990; Weber, 1992), psychoanalysis (Freud, 2002; Fabricius, 2004), theology and philosophy (Levinas, 1969; Augustine, 1991; Benjamin, 1996; Nietzsche, 2009), anthropology (Benedict, 2005), as well as strands of sociology and psychology (Bielby and Bielby, 1988; Elvin-Nowak, 1999), have examined the phenomenology and cultural history of guilt.

For example, analysing the cruelty of beliefs such as the eternal damnation and the widespread fear accompanying them, the French historian Jean Delumeau (1990), spoke of a 'collective guilt complex' that dominated western, or Catholic European, culture between the thirteenth and eighteenth centuries. Benedict (2005; cf. Scheff, 1994) among other anthropologists, in her controversial work, distinguishes between 'shame societies' (e.g. Japan) and 'guilt societies' (e.g. Western Europe), where the former are usually defined as 'primitive', while the latter as 'developed'. On his part, Freud (2002, p.71) who asserted that guilt is mainly unconscious, resulting from a conflict between the aims of the superego (i.e. internalised social norms and ideals) and those of the ego, in Civilization and its Discontents went as far as to say that it was his 'intention to represent the sense of guilt as the most important problem in the development of civilization'. The importance of guilt as an emotion in western culture has also been immortalised in brilliant pages of writers like Shakespeare (1992), Dostoyevsky (1976) and Kafka (2001).

We cannot but be reminded of Nietzsche's (2009) genealogy of guilt. Nietzsche famously identified a similarity in the German words for 'guilt' (Schuld) and 'debt' (Schulden), suggesting that originally guilt had nothing to do with accountability or immorality. Instead, guilt meant simply that, based on the contractual relationship between the creditor and the owner, a debt needed to be paid. According to Nietzsche, this 'original' meaning of guilt changed over time or was suppressed, and was replaced with our now more familiar meaning of responsibility and morality. This relation between guilt and debt, as will be demonstrated, plays a significant role in our argument. A common denominator in all these discourses seems to be that guilt functions as a mechanism of normative control. Nietzsche is explicit on this point; for him guilt is a mechanism for 'self-discipline, self-monitoring, [and] self-conquest' (Nietzsche, 2009, p.106). Indeed, guilt is generally associated with responsibility, action, duty, and remorse. Guilt means being responsible for failure.

Partly drawing inspiration from Nietzsche's musings on the 'origins' and functions of guilt, we see guilt as a constant feeling of imperfection arising in situations where the subject finds it impossible to live up to certain standards. As an emotion, guilt has a tendency to silence and paralyze. Guilt leads the individual to blame himself, to hold himself accountable for his misfortunes. What interests us here is that in neoliberal societies guilt is strongly linked to and exemplifies the 'individualization' 1 of social and political issues such as work and unemployment. In our view, individualization signifies, in some sense, a retreat from organized collective resistance and mobilization based upon class. The strong prevalence of layoffs and outplacement services, their 'normalization', which in turn reflects the dominance of the neoliberal ideology and practices, is a good proof of that. As Bauman (2002, p.xvi) argued: 
'If [individuals] stay unemployed, it is because they failed to learn the skills of winning an interview or because they did not try hard enough to find a job or because they are, purely and simply, work-shy. If they are not sure about their career prospects and agonise about their future, it is because they are not good enough at winning friends and influencing people and have failed to learn as they should the arts of self-expression and impressing others. [...] Risks and contradictions go on being socially produced; it is just the duty and the necessity to cope with them that is being individualised' (emphasis ours).

Furthermore, Rose's (1999) and Dean's (1995) governmentality-based works on 'responsibilization' and the government of unemployment provide us with useful conceptual tools for examining individualization and guilt as they address the widespread trend in making individuals responsible and accountable for their own security, competence, welfare, and 'well-being', including employability. Guilt is indeed a common reaction of individuals, for example, when facing layoffs or when they are unable to 'get back to work'. Responsibilization is connected with the process of 'psychologization', the tendency to treat socio-political issues in a largely individual and psychological fashion. The discourses of autonomy and responsibility, as Crespo and Serrano (2010, p.56) put it, 'undermin[e] collective resources (both conceptual and institutional), which could enable workers to exercise a certain amount of control over the asymmetrical nature of certain employment situations which make them vulnerable'.

Guilt might be the outcome of such structurally produced but individually dealt with situations. The ever-growing demands placed on us under neoliberalism - not only in workplace contexts - to be active and autonomous, determined, to become more efficient, to meet objectives and deadlines, to work harder and longer, and to compete are the objective substratum on which subjective reactions like guilt spring. It is the often insatiable nature of such demands that are internalised by the subject who is positioned as perpetually indebted to her/himself, ever seeking ways to escape this irreconcilable conflict between always having to become more and the unreachability and unachievability of goals and inspirations. 'More' often means and is experienced as 'never enough'. To paraphrase Nietzsche (2009, p.74), neoliberalism tends to make individuals feel 'so guilty and reprehensible, that there is no atonement'.

With this in mind, we looked at management and organization studies literature for works that examine and reflect on the issue of guilt in contemporary organizations. To our surprise, there is very few studies in Organization and Critical Management literature where, even if not explicitly mentioned, guilt is critically examined by looking at its relationship to corporate culturing, organisational control and resistance (Barker, 1993; Casey, 1999; Ford and Collinson, 2011; Spicer, 2011). Most studies on the topic of guilt are of managerial orientation and focus primarily on work-life balance and downsizing practices (e.g. as 'survivors' guilt'). We therefore decided to focus explicitly on downsizing and guilt.

As our work is a conceptual paper that draws upon secondary materials, our theoretical investigation begun with a systematic overview of the existing management literature. More specifically, in terms of our material collection, our literature sample was comprised by peer-reviewed journal articles written on the subject of guilt and downsizing, with key contributions located as far back as mid-80s. Initially we looked for the pair of keywords "guilt" and "downsizing", to be jointly found in title, keywords or abstract of our sample literature. Our investigation was focusing on sub-fields of management (organization studies, critical management and sociology of work), and as our research progressed we opened up our investigation to more keywords that are attributed the same meaning and often used interchangeably in the relevant literature 
such as that of "layoffs", "rightsizing", "restructuring" or "delayering", all jointly found with either "guilt", "employees' emotions" or "employees' feelings". As we later argue in our work, the existing literature primarily focuses on the impact of these practices on organisational performance and what should companies do to minimise organisational disruptions. The negative impact (e.g. stress, anger, guilt) of such practices on employees' psychic are of course acknowledged; yet presented more as personal matters and inadequacies while the political dimension of downsizing is rarely questioned. Instead, management literature presents downsizing and layoffs an inevitable part of 'organizational life' and is mainly preoccupied to offer 'recipes' for 'good' practices, often disguised in a more positive language, described as rightsizing, de-layering and organisational restructuring.

Our aim in this paper is twofold. First, to offer a critical review of the literature on guilt and downsizing, by questioning the apparent normalisation of these practices and the financialization of all aspects of organizational life. Second, to examine and reflect on the discursive mechanisms and organisational practices that normalise downsizing and reproduce individualistic explanations of unemployment, contributing to a heightening of feelings of guilt and of personal inadequacy.

In doing so, we turned our attention to other secondary sources (corporate memos and termination scripts), with the aim to also draw links between the relevant literature on downsizing and how it is actually implemented by contemporary organizations. These sources were selected because they meet three important conditions: a) they were publicly available, $b$ ) they constituted a representative sample of the memos and scripts we could find, and c) they shared commonalities with the key concepts and themes that we had identified in our overview of the relevant management literature. When analysing these memos and scripts, we looked for common ideas and themes (e.g. the importance of proper 'communication', 'organizational support', clear description of organisational 'vision' and emphasis on 'fairness') that cut across the relevant literature and these secondary sources. As we later argue in our work, the discursive normalisation of downsizing identified in the relevant literature goes hand-in-hand with specific organisational processes and practices implemented during downsizing.

For the purpose of our study we describe these processes as three, separate but interconnected, phases of downsizing. We analyze corporate memos (phase 1), termination scripts (phase 2), and, then, the role of outplacement services (phase 3), in order to critically examine the processes and mechanisms through which the normalization and individualization of downsizing and unemployment is produced, arguing that the feelings of personal responsibility, self-blame and inadequacy reinforce individualistic understandings of work and unemployment, exclude more structural ones, and reproduce the existing structures of power. We conclude that the political and social significance of the sense of guilt $t^{3}$ in these terrains has been largely ignored and that further research on how guilt is produced through corporate discourses as well as through a set of corporate practices that privilege the individual, requires theoretical investigation and political contestation.

\section{Downsizing and guilt}

The existing literature on guilt is mainly of managerialist orientation and focuses on 'work-life balance' (Simonetti et al., 1993; Hochwarter et al., 2007) and organizational downsizing with reference to 'survivors guilt' (Wiesenfeld et al., 1999; Brockner et al., 2004; Drzensky and Heinz, 2015; Snorradottir, et al., 2015) and 'survivor syndrome' (Travaglione and Cross, 2006). Within this body of literature, the focus is on the 
negative impact of guilt on employees' emotions and organizational performance as well as the perceptual differences between 'survivors' and 'victims' and how that impacts on organizational issues such as that of morale, trust, job satisfaction and commitment (Reinardy, 2010; McDevitt et al., 2013). Some studies have also tried to explore the potentially 'positive' effects of guilt on organizational performance. It has been argued that albeit a negative emotion for the individual, guilt can have some constructive potentials for the organization as it fuels employee commitment (Li et al., 2010) and generates 'altruistic behaviour' (Flynn and Schaumberg, 2012), thus enhancing a sense of responsibility towards the corporation.

Given that since Hochschild's (1983) seminal study on emotional labour, the role of employees' emotions and feelings in organizational life and how they relate to the (re)production of work identities and issues of power and resistance have been thoroughly scrutinised (Kunda, 1992; Rodrigues and Collinson, 1995; Gabriel, 1997; Collinson, 2000; Garrety et al., 2003; Coupland et al., 2008), it is surprising that the topic has not attracted more research in organization studies.

Downsizing begun receiving some attention in the 1980s and became a management catch-cry since the wave of downsizing that characterised corporate capitalism during the 1990s, a period also known as the 'downsizing decade' (Wager, 1998, p.300; see also Cohen, 2009, p.33; Lilley, 2010, p.6). The term downsizing originally referred to strategies of personnel redundancies, but it is more broadly used to signify organizational changes (Gandolfi and Hansson, 2011). The body of literature on downsizing is substantial and reflects its strong prevalence not only in the US (e.g. Budros, 1997) and other western countries but also in Japan, countries of Latin America, and those relatively recently moved to a market system such as Eastern European countries (Appelbaum et al., 1999). That prevalence and subsequent normalization of downsizing practices reflects the dominance of the neoliberal worldview and the precariousness of labour where thousands of companies (both private and public) and the lives of millions of employees (irrespective of position, educational background, age or gender) have been transformed. Even those workers traditionally considered as 'advantaged', such as public sector workers and middle managers, have been affected by downsizing (Picot and Lin, 1997; Worrall et al., 2000; Gandolfi and Neck, 2007; Silver et al., 2009) $)^{2}$, something that is also depicted in films such as Up in the Air (2009) and The Company Men (2010).

Downsizing emerged with the end of the post-war settlement between capital and labour. The 'old employment contract' where employees enjoyed relatively high incomes and employment security for technological and other disempowering changes, was replaced by what became known as the 'new psychological contract', accompanied by the loosening of the employment relations and the decline of trade-unionism (on the political and ideological aspects of neoliberalism see Lazonick and O'Sullivan, 2000; Martin, 2002; Amoore, 2004; Harvey, 2007; Streek, 2011). The new model of organizing work and the employees-organizations relationship promised to employees 'genuine autonomy' in their work and an opportunity to be transformed into 'winners' through a range of anti-bureaucratic management techniques, from lean management to business process re-engineering. The neo-management rhetoric, as Boltanski and Chiapello (2007, p.76) argue, 'is filled with exceptional beings, proficient at numerous tasks, constantly educating themselves, adaptable, with a capacity for self-organization and working with very different people'.

Behind this post-bureaucratic rhetoric on building a more resilient and responsive organization with superior efficiency lurk new forms of discipline and control (Courpasson, 2000; Knights and Wilmott, 2000). Downsizing practices (in the form of 
layoffs, early retirement, delayering or restructuring) constitute a commonly used method for building the 'new' organization, yet as several searchers are pointing out, it is but the 'necessary' consequence of cost cutting and the consolidation of redundant operations. This is often combined with the 'adequate' distribution of cash flow to stakeholders and the development of market access strategy so as to gain 'competitive advantage' in the global economy, a process described by Nolan and Croson (1995) as 'creative destruction' (in Schumpeter's expression). But much more than this, downsizing has been a disciplinary mechanism against labour's power (Turnbull, 2001; Siemiatycki, 2012). In North America, for example, permanent restructuring is strategically used by capital to continually intensify the demands placed on labour in order to possibly expand its accumulation (Siemiatycki, 2012). Gandolfi and Neck (2007, p. 20) importantly add that 'downsizing is not only employed as a strategy to cut labor costs by shedding labor in the short run, but also to apply downward pressure on wage demands from the remaining workforce in the longer term'. In similar fashion, Osthus's (2007, p.746) empirical study on the effects of downsizing on Norwegian workers' well-being and health concluded that 'demands on employees to exert more effort seem to be the usual outcome of downsizing and organizational redesign [as] recent workplace changes on average are causing employees to suffer from an effortreward imbalance'. The decline of trade-unionism in western countries since the 1980s as in other regions of the world (ILO, 1997; Kuruvilla et al., 2002; Baccaro, 2008; Nowak, 2015; Jung, 2017; Koçer, 2018) has clearly contributed to this phenomenon. The available literature also indicates that trade-unions may still play a significant role in negotiating downsizing with varying results. We need however to recognise the institutional conditions impacting on the ability of unions to successfully resist downsizing and the form that labour opposition might take. For example, Noda et al. (2013) nicely describe the transformation of trade unions (or enterprise unions, as they call them) since 1997 in Japan how changes in the union's stance towards downsizing practices affected employment adjustment behaviors. Similarly, Isaksson et al. (2005), in their study of a union-friendly organization in Sweden, described the collaborative role of the union during the implementation of the downsizing process in negotiating favourable agreements for its members, although unable to reverse the termination of contracts or reduce the number of redundancies. Last, but not least, Jung (2017) examined how labour union resisted the shift from temporary to permanent termination in large US corporations between 1984 and 2006. He concluded that, despite the hostile political environment that had significantly weakened labour union power; unions resisted layoff policies both by discouraging firms from making permanent layoffs through direct confrontation and by bargaining with firms for more reliance on temporary layoffs at times that permanent terminations seemed inevitable.

Going back to the literature on organizational downsizing, early studies were quantitative and laboratory based (Brockner et al., 1985; Brockner et al., 1987) and formed the basis of many subsequent studies on the emotional responses of employees surviving a layoff. The literature on so-called 'survivors guilt' suggests that in most cases guilt constitutes a 'negative' experience for the employees which can lead to lower levels of commitment and loyalty, a distrust of top management and poor performance. A range of researchers and practitioners point to the ineffectiveness of poorly executed redundancies to produce the desired outcomes and emphasise that downsizing strategies should be carefully planned and executed (Tomasko, 1991; Cameron, 1994; Kets de Vries and Balazs, 1997; Noer, 2000; Campell-Jamison et al., 2001; Cascio, 2002a,b; Brockner et al., 2004; van Dick, et al., 2016; Bergstrom and Arman, 2017). For example, Cameron (1994) and Cascio (2002a, b) argue that poorly 
executed redundancies can generate resentment and resistance leading to sabotage and workplace violence from aggrieved or former employees. In the US, programs such as Leading Downsized Organizations were developed in order 'to provide individuals with a process for dealing effectively with the human side of downsizing' (Noer, 1995, p.28). For Noer - a writer of 'seemingly social Darwinist leanings', as Archibald (2009, p. 325) remarks - survivors guilt is a 'sickness' that workers have to be 'cured' of. To avoid what he calls 'survivor syndrome', organizations should properly execute redundancies by implementing a specific set of actions (Noer, 1993). These actions include, among others, 'fairness' in the procedure, involvement of the survivors in building the 'new' company, the strengthening of communication with the survivors, and support to the victims. Following this course of actions, he asserts, employees' guilt feelings are less likely to occur. In Noer's (1993, p.31) own words: '[P] eople must let go of the familiar old and venture into the untested new. Healing is, in the final analysis, an individual effort, requiring personal courage'. Survivor guilt is attributed as much to managers for being too attached to their subordinates or to the poor execution of redundancies, as to the employees' 'personal qualities' (Turnbull, 2001), their relationships with their co-workers and their 'psychological attachment' to the corporation. In such cases, survivors' friendships and other social relationships with their laid-off co-workers often become tense or are terminated (Glover, 2010).

But just as the survivors may experience guilt, so do the victims ${ }^{3}$ (Hallier and Lyon, 1996; Sennett, 1998; Uchitelle, 2007) and, as we will later discuss, the terminating managers too (Tyrrell, 1994, n.p.). The laid-off employee turns the blame to him/herself: 'I should not have been so dependent to my employer'; 'Only if I had done this course'; 'I did not work hard enough'. These are some of the typical responses by laid-off employees. Reflecting on a conversation between ex-IBM technicians subjected to a layoff, Sennett (1998) describes how the initial interpretation of their dismissal as 'the victims' of the corporation later switched to their own behaviour. The initial feelings of betrayal gave their place to external forces (eg. 'the global economy') as the source of their misfortune. But near the end of the conversation, the blame was turned towards their behaviour and responsibilities. They were responsible for being 'too company-dependent', for 'not getting out on time'. Describing their predicament as an outcome of personal choices resulted in an individualising understanding of their unemployment, underrating the structural causes that would, in turn, require political solutions.

This depoliticization of unemployment, as Sharone (2007) explains, is produced and further reinforced by discourses on 'employability' and a particular engagement in the job searching 'game'; one that requires 'job-seekers' energy to be directed towards 'strategic' choices and individual level manoeuvres. To this end, researchers of a managerialist orientation make explicit reference to personal responsibilities in finding a new job, suggesting that the extent of the period that they remain unemployed is merely a result of their individual determination and commitment (Kanfer and Hulin, 1985; Noer, 1993; Kets de Vries and Balazs, 1997). A quick search in the available literature, websites of career advisors, self-help programs, and outplacement services immediately reveals myriad 'success stories' of individuals who lost their jobs but did not gave up, of extraordinary people with determination and proactive personalities, who, unlike those with the 'victim syndrome', took control over their lives and turned the threat of unemployment into an opportunity for a new beginning.

Noer (1993) tells the story of Juanita, a middle-aged employee working as a department director in a high-tech firm. Despite her commitment to 'life-long learning', Juanita eventually lost her job but with the assistance of her company and her personal 
determination and commitment - 'a fair amount of money on her psychological counselling and outplacement services' (Noer, 1993, p.5) - her efforts were worthwhile as she found a job as a principal in a small but growing consulting firm and was excited with the new life which provides her a 'work-life balance' previously impossible. In similar fashion, Kanfer and Hulin (1985) examined the relationship between 'selfefficacy' and 'reemployment', arguing that individuals' low self-efficacy expectations are more likely to prolong the unemployment period. Kets de Vries and Balazs (1997, p.26) went even further, arguing that individuals' unemployment is often prolonged 'because of their depressive outlook towards things, their fear of not being able to find another job could become a self-fulfilling prophecy'. Thus, unemployment has been mainly understood in individualistic and behavioural terms, where 'job-seeking' requires 'flexible strategic choices' and 'positive attitude'.

In short, the existing management literature presents downsizing as a natural phenomenon of contemporary organizational life that if properly executed could have positive effects both for the organization and the employees. Illustrating the diverse facets of finance's spread in everyday life, Martin (2002, p.109) remarks that 'by describing negative outcomes of social life in terms of risk, unpredictabilities of the market like layoffs through downsizing could become integrated into the experience of the employed as an ongoing uncertainty that all would have to live with', yet, so management gurus argue, with 'liberating' potentials for the employees nevertheless. Having briefly discussed the link between downsizing practices and guilt, we will turn now our attention to this process of individualization by examining corporate memos and termination scripts used by organizations as well as the role of outplacement services. We will argue that feelings of personal responsibility and inadequacy are heightened by corporate downsizing practices.

\section{Downsizing practices and the depoliticization of work}

So far we have drawn some connections between guilt and the normalization of layoffs as they constitute part of the increasing individualization of work. Business research focuses on the 'negative' emotions that downsizing practices generate both to the victims and the survivors and warn managers of the potential disruptive consequences for the organizations (e.g. Marques et al., 2014; Kawai, 2015; de Jong et al., 2016; Schenkel and Teigland, 2017). To manage and prevent these 'negative' emotions, a whole series of organizational actions before, during and after the layoffs has to be developed and employed. As many management gurus (Cameron, 1994; Brockner et al., 2004; Bergstrom and Arman, 2017) argue, a 'recipe' for a successful downsizing has to include 'objectiveness' and 'fairness' in the procedure, it has to point to the inevitability of such practices and provide a vision for the future of the organization. Equally important is to cultivate a sense of involvement in employees both in the downsizing procedure and in re-building of the organization.

For our part, we will focus on downsizing practices and reflect on the discursive practices that contribute to the depoliticization of work and unemployment by utilising individualistic explanations and by creating feelings of guilt. We believe that these practices are divided into three separate, but interconnected, phases. The first phase, the pre-downsizing phase, that often has several stages of its own, primarily focuses on communicating the news in a rather convoluted language, aiming to mask bad news messages through the use of euphemisms such as 'restructuring', 'delayering' or 'rightsizing'. Even in cases that there is an explicit reference to 'layoffs' (Jerry Yang's email to 'Yahooers', appendix B) or 'part[ing] ways' (Dorsey's email to Twitter 
employees, appendix D), careful attention is placed in presenting the forthcoming changes as a result of external circumstances and/or carefully conceived strategic vision for the future of the organization, while there is also much emphasis on sympathy to the affected employees and a strong culture of 'caring'. Moving to the second phase of the downsizing practices, we begin to see the emphasis shifting more towards the management of employees' emotions and potential resistance. Through the use of termination scripts, the decision to downsize is finally announced to all parties involved; yet, again careful attention is given to the ways in which this news is communicated to both survivors and victims of layoffs, creating a distance between those responsible for executing the layoffs and those subjected to layoffs by pointing to the 'fairness' and 'objectivity' of the whole procedure. The last phase, the postdownsizing phase, is a period of rebuilding employees' trust and commitment to the organization through a range of managerial interventions, while at the same time reinforcing to the laid-off employees an individualistic understanding for been laid-off. In all three phases, we argue, there is a discursive mechanism that gradually shifts responsibility towards the laid-off employees. As we will show below, we believe that these discursive practices not only normalise downsizing but also reproduce individualistic explanations of unemployment which in turn contribute to a heightening of feelings of guilt and of personal inadequacy. Having said that, we of course recognise that laid-off employees' reactions are not only unpredictable but also constantly evolving, depending on personal and social circumstances. Hence, we should be wary of generalizations and deterministic assumptions.

\section{The pre-downsizing phase: The communication of forthcoming downsizing practices}

In the first phase of the downsizing practices, as already pointed out, emphasis is placed on communicating management's intentions to the employees. This process consists of many different layers such as verbal and written communication and body language. We will, however, focus on written communication and more specifically on corporate memos as they are commonly used to mitigate the short-term effects of delivering bad news and set the ground for implementing organizational changes with the least possible disturbances. For the purpose of our analysis we have chosen four corporate memos (Appendix A-D) from well-known multinational corporations that have been widely cited in the available literature (Arrington, 2008; Swisher, 2008, 2009; Warnick, 2010; Shontell, 2015) and in our view are representative of the corporate language used across organizations during periods of organizational downsizing.

Looking at these corporate memos, the first similarity we observed is that emphasis is laid on external circumstances, from the uncertainty and challenges in the business environment to the deteriorating effects of the financial crisis which had then just emerged:

'[W]e as a company have been through a tremendously challenging year; and managing the increasingly turbulent global advertising climate has been an important focus for the last three months [...]' (Appendix B)

'In response to the realities of a deteriorating economy [...]' (Appendix A) 
'As all of you are aware, industry conditions have been challenging due to the financial crisis, which has produced sharp decreases in advertising spending. This is expected to continue through most of 2009.' (Appendix C)

Reference to the 'new reality' and the 'deteriorating economy' rationalise the forthcoming layoffs as inevitable and beyond the organization's control, while the reference to external factors such as the 'recession' and the 'financial crisis' diverts management's responsibility for the layoffs to some scapegoat. At the same time, we can see hints of the forthcoming layoffs, hidden in euphemisms such as 'reducing layers' (appendix B) and 'restructuring' (appendix C and D) coupled with a recognition of the uncertainty that such actions cause to the workforce and a vision for the future of the organization:

'[W] e understand that hearing this news now creates uncertainty, but we are moving ahead in a way that balances speed with a clear focus on accomplishing what is necessary to set the organization up for long term success.' (Appendix B).

'We are moving forward with a restructuring of our workforce so we can put our company on a stronger path to grow.' (Appendix D).

'The goal is to enable our company to move faster, go to market smarter, save significant costs, and employ our editorial resources more efficiently.' (Appendix C)

'These moves are really about our continued efforts to create a more agile and efficient organization that can thrive in a time of constant change.' (Appendix E)

By simultaneously showing sympathy to the to-be-affected organizational actors and a vision for the future, the disciplinary character underpinning downsizing practices is presented as a 'strategic choice' driven by a vision for the long-term success of the organizations and the wider interests of its stakeholders. The narrative of hope that the aforementioned extracts convey, presents the laid-off employees as an inevitable but necessary 'collateral damage' for the 'wider good' of the organization. This is further reinforced by the use of narratives of a 'fitter', 'stronger', 'efficient' and more 'responsive' organization (see for example, appendix B, C and E), implying that the laid-off employees constitute extra weight, that they make the organization weaker, inefficient and non-responsive. This is a rather crucial observation as we begin to notice how the reference to the external environment gives place to the vision of the organization and the great future ahead. What is more, there is shift of responsibility towards the individual through the mechanics of hidden messages that nevertheless give to a text a particular rhetorical effect.

Moreover, as downsizing signifies discontinuity and 'organizational death' which can constitute a profound source of loss and suffering, the articulation of a vision for the 'new' organization signifies transition and continuity rather than an ending. Despite the convoluted language used in these memos to announce the forthcoming layoffs, the available literature suggests that such news create feelings of uncertainty and profound 'stress' to the employees, leading to 'undesirable' reactions: from high levels of absenteeism and turnovers to low levels of commitment. To manage these reactions, management gives emphasis to their intention to support the laid-off employees, as illustrated in the following extracts: 
' $[\mathrm{H}]$ aving layoffs is very difficult, particularly in light of all we've experienced this year. [B] ut we don't take these decisions lightly, and are committed to treating affected employees fairly, offering severance and outplacement services' (Appendix B).

'I know this will be a difficult time for you and I want to assure you that we will provide help and support during this transition. We have established an outplacement center in the Puget Sound region and we'll provide outplacement services in many other locations to help you find new jobs' (Appendix A).

Taking responsibility for the 'transition period' serves a dual purpose. First, it indicates a 'caring' culture both to the victims and the survivors and helps in neutralising negative reactions and enhances a perceived fairness to the procedure. Secondly, by showing support to the laid-off employees through outplacement or other consulting arrangements designed to help them acquire the supposed necessary skills and knowledge to become 'employable' again, an individualistic explanation of unemployment as a result of not possessing the necessary skills or qualities is reinforced. Such interventions contribute to the formation of individuals' selfunderstanding in relation to employment or, in this case, unemployment. This in turn creates an irreconcilable tension between the limits of the laid-off employee material reality and its own ideal of full self-realization. As in the case of the IBM workers (Sennet, 1998) discussed earlier, laid-off employees turn the blame inwards, creating a conflict between 'what they are', that is their actuality, and 'what they ought to be', an ideal other version of themselves.

\section{The downsizing phase: Managing employees' reactions using termination scripts}

In the second phase of the downsizing process, as already pointed out, there is a shift of emphasis to the 'fairness' and the 'objectivity' of the whole procedure and to the organization's intention to provide support both to the survivors and the victims. According to many researchers and practitioners in the field, organizations have to convince the to-be-laid-off employees and the survivors that downsizing is not only necessary for the future of the organization but that it is also based on 'objective' and 'fair' assessments. We would like to focus on two issues that emerged from our research. The first relates to the use of specific termination scripts (Tyrrell, 1994) and external consultants, and the second to the emphasis placed on the 'fairness' and 'objectivity' of process which is embedded in the ideology of meritocracy. We therefore hope to demonstrate how organizations aim to manage both managers' and laid-off employees' emotions and their potential practices of resistance and how the individualization of the layoff process is institutionalised through specific discursive practices.

Tyrrell's (1994) work provides a detailed account of the corporate firing practices developed by outplacement specialists. The use of termination scripts helps to alleviate employees' unwelcome reactions during the downsizing process and at the same time reassures the managers involved in the process that the decision to proceed with redundancies was inevitable, which in effect converts managers' 'potential guilt into a recognition of fate' (Tyrrell, 1994, n.p.). Tyrrell identifies three steps in the termination scripts, each playing a specific part in the firing process: the news, the support, and the close.

In the first step, considerable attention is given to the announcement and justification of the decision to the victim. Unlike the pre-downsizing phase that we discussed earlier, the announcement takes place in a face-to-face meeting with each dismissed employee 
which is a stressful experience for all the parties involved. Therefore, use of phrases such as 'it is with regret that I must advise you...' (appendix F) presents the manager as just 'the messenger' of the news, as someone who had to deliver the news and is not in any way responsible for the actual decision. In doing so, not only are employees' potential reactions to the announcement of the layoff neutralized but they also allow the manager responsible for delivering the news to manage his/her emotions during the process, as is commonly reported. As Tyrrell (1994, n.p.) explains, the use of special counsellors that train and advise the terminating managers during the rehearsal and pretermination meeting sessions, serve to 'reassure the managers that the termination was inevitable [and] beyond their control'.

When the decision is finally announced, the focus shifts to the organization's intentions to support the dismissed employees both materially and psychologically, something that signals a 'caring' culture:

\section{Material Support}

'What I would like to do now is to review with you the details of your termination package. The company is prepared to offer you a separation package which includes statutory requirements, plus severance for a total of ... etc'.

\section{Psychological Support}

'The company has retained, at our own expense, the firm of Work transitions Canada to help you in your job search. While it is entirely up to you, I would encourage you to take full advantage of their services and programs to help you find other employment' (Appendix F).

At this phase, the discursive use of 'support' has numerous purposes. First, it signals that the decision is final and discourages employees from bargaining their way back to the company. Second, it alleviates managers' feelings of guilt and stress and at the same time makes the laid-off employees feel the company is there to support them, which in turn reduces their resistance towards management's decision.

The process ends with the 'psychological' and 'physical' close. The 'psychological' close marks this discontinuity, aiming to sever any emotional bonds between the employees and the managers. This psychological distancing is then reinforced by escorting the laid off employee outside the office (Tyrrell, 1994).

We could therefore note that the use of scripts has multiple purposes as they are not only directed towards the laid-off employees but also towards those responsible for executing the layoffs. Yet, the effects of the scripts on them are profoundly antithetical. In the case of the laid-off employees we can clearly see both the hidden and visible mechanics of reinforcing an individualistic understanding of work and unemployment. In the case of the manager though, we observe that the use of scripts serves as a tool to distance them from any feelings of personal responsibility or any accountability to the laid-off employees so that to make, what is otherwise a very stressful experience, a tolerable process. As nicely depicted by Smith (1994, p.52):

'[W]hen James Smith, 47, a division manager in Indianapolis, had to fire 20 of his 80 subordinates in 1988, he fretted that if he had led his troops better he might have prevented the downsizing. His guilt grew into a sense of personal failure. "I would characterize my reaction as depression," he says, "waking up at 2 A.M., crying at times, feeling out of control of things" [...] He [James Smith] is still cutting staff, but AT\&T has made the anguish of his assignment more bearable. The company has taken great pains to explain how changes in the global marketplace and not managerial failures forced the restructuring.' 


\section{The post-downsizing stage: Outplacement services and the individualization of unemployment}

Moving to the last phase of the downsizing practices, psychological counselling and consulting arrangements constitute commonly used tools by management to signal a 'caring' culture for all employees and help both the survivors and the victims to cope with their 'loss' and go on with their lives. The role of various consulting arrangements in the normalization of layoffs and the shifting of responsibility to the individual can be found in the works of Utchitelle (2007) and Sharone (2007). Utchitelle's example of the aircraft mechanics of United Airlines in Indianapolis illustrates how outplacement services, themselves sponsored by a coalition between companies, trade-unions, government and civic groups, eventually served as a means to transform the threat of unemployment into an individual responsibility. Those programmes passed the message that those laid-off mechanists needed only to acquire the 'right' education and skills and jobs will materialise. It is the workers' responsibility to acquire the necessary skills and knowledge, to become 'employable', yet if the transition to new careers fails to materialise then that is due to personal 'defects', reluctance to move to places where there is demand for jobs or unwillingness to acquire new skills. Therefore, outplacement services reinforce the individualization of unemployment by discursively excluding the structural, economic forces behind unemployment.

In the remaining part of the paper, we will examine the emotional aspect of consultation in order to illustrate how such consulting arrangements shift once more the responsibility towards the individual. We will argue that the discursive practices of job hunting and employability contributes to the heightening of guilt feelings in the jobseeking subject, a subject that is 'capable of becoming always more than what she/he is' (Costea et al., 2012, p.26), hence perpetually guilty for not reaching his/her goals and targets.

Outplacement, or 'career transition', is either used after the laid-off employees have left the organization or can be brought to the organization to assist the implementation of the layoff (Gribble and Miller, 2009). Outplacement services provide pseudo offices with administrative staff to assist clients with things such as the posting of job applications and access to phones, faxes and computers, training in job searching activities such as preparing CVs and using networking as a means of gaining employment, career counselling, psychological assessment, and financial counselling. Some of the provisions of a typical outplacement firm include a 'review of individual's resume', 'skill assessment', 'evaluation of personal and professional social media accounts', 'networking' and 'coaching' (see for example, http://www.pdpeurope.ch or http://sanfordrose.com/). The targets of these services are the candidate's skill base, career goals, and ability to 'network'. Consider the following example of how the aforementioned US outplacement company markets itself:

'The DBM transition is anchored in our Focus-Prepare-Achieve model - proven methodology, based on adult-learning principles and focused on a series of identifiable outcomes that drive transition success. Our approach provides real-world flexibility with the assurance of consistency and quality' (http://www.dbm.com/gb/en/about_dbm.asp).

The language of such services is, rather unsurprisingly, highly individualist and depoliticizing. The discourse of 'flexibility', 'preparation' and 'success', based on the supposedly scientific principles of 'adult learning', diverts the attention away from the 
political economy of unemployment. Here is an example of how another US outplacement company advice its potential clients to work with them:

'In this era of corporate restructuring and downsizing, anyone can lose a good job with little notice. Therefore, it's a good idea to establish an early relationship with SRA. If you should unexpectedly lose your job, we'll be ahead of the game by already knowing the kinds of opportunities that will be attractive to you. [...]. Career development is a serious process. If you use an opportunity that a Sanford Rose Associates - Greensboro Search Consultant has presented to you simply to "shop" or to try to establish your market value, you are doing yourself a disservice and are wasting everybody's time. There are less risky and more costefficient ways to establish your worth' (Sanford Rose Associates, 2018, n.p. - emphasis ours).

The outplacement provider is at once a 'psychologist, confidant, aide and friend' (Doherty and Tyson, 1993, also quoted in Gribble and Miller, 2009, p.11), s/he is there to reassure the unemployed job seeker that no matter how discouraging the market may be, finding a job is a matter of personal effort and determination. If the unemployed subject cannot find a job, it is because $\mathrm{s} / \mathrm{he}$ is not trying hard enough to make the most of out of his/her situation, because s/he is not having the 'appropriate' attitude. Even when there are not enough jobs available, as is very often the case, guilt, self-blame and loss of self-esteem and identity is a common experience.

The wider process of responsibilization has been well-documented. Sharone's (2007) ethnographic study of unemployed 'job seekers' in the US provides a colourful account of the depoliticization of unemployment through discourses of 'employability' and a set of practices that emphasise individuals' control. We have to however acknowledge that we should be sensitive to specificity of the national context, which is in this case to a great extent individualist, so as to again avoid generalizations and easy conclusions. For example, Sharone (2013) argues that, while in the US, unemployed job seekers tend to blame themselves for their labour market difficulties, in Israel they tend to blame the hiring system. This depoliticization of unemployment is, however, neither restricted to a specific class nor the product of the isolation of the unemployed job seekers 'since it persists even when [they] gather with others who are experiencing similar hardships', like Sharone (2007, p.404) notes. The practices of outplacement services, exemplified by self-help manuals, individualise unemployment by channelling the individuals' practical energies toward strategic decision-making and individual level manoeuvres and away from larger structural contexts. These practices have a seductive character as at best they diminish employees' resistance to downsizing practices by giving emphasis to a self-help paradigm and at worse make the unemployed job seekers to feel as losers and to blame themselves for their predicaments. This is evident in Sharone's work where job seekers privilege individual responsibility over external factors and rationalise their unemployment as a result of personal shortcomings. To be actively engaged in these 'work-games', as she calls them, require job seekers to invest all their energy into developing special skills in searching for a job and divert their attention from the larger context of the labour market to personal decisions, privileging individual control. As Sharone (2007, p.412) puts it, 'the practical lived experience of playing the game engenders a sense of total individual control'. Even when some job seekers manage to avoid self-blame by questioning the individualising self-help discourses, they rarely express their doubts or criticism publicly in fear of being seen as 'losers'. This is due to expert speakers' emphasis on self-help and personal control as well as to the set of practices in the outplacement services which privileges the individual and convey the message that job seekers need only to put enough effort and have the proper attitude and a job will materialise. 
In short, we have tried to describe the three phases of the downsizing practices and the specific individualising language and norms that supports them, which results in transforming social and political issues and problems into personal challenges and inadequacies. The use of corporate memos, termination scripts and outplacement services contribute to the depoliticization of downsizing practices by reproducing individualistic explanations that heightening feelings of guilt and self-blame and extend the downward spiral of layoffs and guilt, unemployment and guilt.

\section{Conclusion}

It is not too far-fetched to suggest that the pervasiveness of downsizing practices, particularly in contemporary neoliberal western societies, reflects neoliberalism's dominance and the precariousness of labour. Yet, despite of the political and social significance of the emotion of guilt, organization studies scholars have paid little attention on how guilt is conceptualised in various managerialist literatures and on how it functions as a normative mechanism and is linked to the 'individualization' of social and political issues such as work and unemployment. In sharp contrast, researchers of a managerialist leaning have considerably examined the effects of guilt on employees and organizations, offering practical solutions to organizations in terms of 'best practices' when executing redundancies while at the same time presenting its effects on employees' lives in strictly individualistic and behavioural terms.

By examining corporate memos, termination scripts and the role of outplacement services, we have tried to illustrate some of the processes through which the individualization of work and unemployment is produced. Our analysis of the downsizing practices indicates that the ideology of individualism prevails over alternative explanations and solutions to such public issues precisely because it is fundamentally embedded in downsizing and outplacement services' discourses and practices that emphasise individuals' control and willpower. We have moreover demonstrated that guilt is a normative mechanism which is linked to the wider trends of individualization and responsibilization of citizens, employees and job seekers prevalent in our societies, and which reinforces an individualistic, neoliberal attitude to social and political issues, in other words to situations that may be far outside their control, such as keeping their jobs. It is, however, important, to stress that the guilt feeling is not the 'privilege' of the surviving or laid-off employees but is something that may also affect the management team which is responsible for executing the downsizing decision. Research into the management and politics of emotions such guilt should not be restricted only to employees but should encompass managers' guilt feeling, such those as the terminating managers involved in the downsizing process.

We may conclude that as long as employees embrace the individualistic discourses that portray their predicaments as an outcome of personal choices, corporate downsizing practices will remain unchallenged while the structural causes of unemployment, that require political solutions, underrated. Therefore, our conceptual work offers a critical reflection on how guilt is produced through corporate discourses and practices and we hope that this will encourage further empirical investigation during the three phases of the downsizing process and the lived experience of (un)employment. We have tried to reflect on how corporate downsizing discourses and practices frame (un)employment in strictly individualist and behavioural terms and emphasize the need for further theoretical investigation and political contestation. We therefore hope that our work will contribute to the relevant literature on downsizing 
practices and open up the discussion around layoff policies (especially in western countries that is the focus of our work) and the structural conditions of (un)employment.

\section{Notes}

1. Whilst individualization is a complex and multivalent notion (Howard, 2007), here we take it to be denoting the widespread assumption that the individual is the fundamental agent of human action.

2. Warnick (2010, p.324) remarks that layoff memos could be both analysed from a Marxist perspective as the overabundance of financial data seem to be institutionally in favour of the stakeholders and from a feminist perspective as the language of such memos are written in a strictly professional and unemotional tone. Furthermore, we should note that we are not so much concerned with the 'ethics' (e.g. Gilbert, 2000; Lämsä and Takala, 2000; Rosenblatt and Schaeffer, 2000; Henry and Jennings, 2004) and the 'interpersonal sensitivity' of such a 'necessary evil' as downsizing (Molinsky and Margolis, 2005). The experiential side of the 'downsizing agents' or 'grim reapers' (Clair and Dufresne, 2005; Gandolfi, 2008; Ashman, 2017) is for us more important.

3. Given the change in the social contract of employment, leading to a model in which flexibility rather than security is given priority (e.g. Lane, 2009) it may be not very surprising if victims do not feel guilty as they consider job loss and change expected and necessary. Let it be noted, moreover, that while unemployment has been normalized, in their meta-analysis, Paul and Moser (2009) found no evidence to support a stronger association of unemployment and lower psychological health than in earlier decades.

\section{References}

Amoore, L. (2004), "Risk, reward and discipline at work", Economy and Society, Vol. 33 No. 2, pp. 174-196.

Appelbaum, S., Everard, A. and Hung, L. (1999), "Strategic downsizing: Critical success factors", Management Decision, Vol. 37 No. 7, pp. 535-552.

Archibald, W. (2009), "Globalization, downsizing and insecurity: Do we need to upgrade Marx"s theory of alienation", Critical Sociology, Vol. 35 No. 3, pp. 319-342.

Arrington, M. (2008), "Jerry Yang email to all yahooers: 10\% of you are fired". Available at: http://techcrunch.com/2008/10/21/jerry-yang-email-to-all-yahooers/ (last accessed on 09/02/2018).

Ashman, I. (2017), "The face-to-face delivery of downsizing decisions in UK public sector organizations: The envoy role", Public Management Review, Vol. 17 No. 1, pp. 108-128.

Augustine (1991), Confessions, Oxford University Press, New York.

Baccaro, L. (2008), "Labour, organization and inequality: Are trade unions still redistributive?", Discussion Paper 192, International Institute for Labour Studies.

Barker, J. (1993), "Tightening the iron cage: Concertive control in self-managing teams", Administrative Science Quarterly, Vol. 38 No. 3, pp. 408-437.

Bauman, Z. (2002), "Individually, together: Foreword", in Beck, U. and BeckGernsheim, E. (Eds), Individualization, Sage, London, pp. xiv-xix.

Benedict, R. (2005), The chrysanthemum and the sword, Houghton Miffin, Boston.

Benjamin, W. (1996), "Capitalism as religion", in Bullock, M. and Jennings, M. (Eds) Selected Writings, Vol. I., Belknap Press of Harvard University Press, Cambridge, pp. 288-291. 
Bergstrom, O. and Arman, R. (2017), "Increasing commitment after downsizing: the role of involvement and voluntary redundancies", Journal of Change Management, Vol. 17 No. 4, pp. 297-320.

Bielby, D. and Bielby, W. (1988), "She works hard for the money: Household responsibilities and the allocation of work", American Journal of Sociology, Vol. 93 No. 5, pp. 1031-1059.

Boltanski, L. and Chiapello, E. (2007), The new spirit of capitalism, Verso, London.

Brockner, J., Davy, J. and Carter, C. (1985), "Layoffs, self-esteem, and survivor guilt: Motivational, affective and attitudinal consequences", Organizational Behavior and Human Decision Processes, Vol. 36 No. 2, pp. 229-244.

Brockner, J., Grover, S., Reed, T., Dewitt, R. and O"Malley, M. (1987), "Survivors" reactions to layoffs: We get by with a little help for our friends", Administrative Science Quarterly, Vol. 32 No. 4, pp. 526-541.

Brockner, J., Spreitzer, G., Mishra, A., Hochwarter, W., Pepper, L. and Weinberg, J. (2004), "Perceived control as an antidote to the negative effects of layoffs of survivors" organizational commitment and job performance, Administrative Science Quarterly, Vol. 49 No. 1, pp. 76-100.

Budros, A. (1997), "The new capitalism and organizational rationality: The adoption of downsizing programs, 1979-1994”, Social Forces, Vol. 76 No. 1, pp. 229-250.

Cameron, K. (1994), "Strategies for successful organizational downsizing", Human Resource Management, Vol. 33 No. 2, pp. 189-211.

Campell-Jamison, F. Worrall, L. and Cooper, C. (2001), "Downsizing in Britain and its effects on survivors and their organizations", Anxiety, Stress \& Coping: An International Journal, Vol. 14 No. 1, pp. 35-58.

Cascio, W. (2002a), "Strategies for responsible restructuring", Academy of Management Executive, Vol. 16 No. 4, pp. 80-91.

Cascio, W. (2002b), Responsible restructuring, Berret - Koehler, Inc., San Francisco.

Casey, C. (1999), "“Come, join our family": Discipline and integration in corporate organizational culture", Human Relations, Vol. 52 No. 1, pp. 155-178.

Clair, J. and Dufresne, R. (2004), "Playing the grim reaper: How employees experience carrying out a downsizing", Human Relations, Vol. 57 No. 12, pp. 1597-1625.

Cohen, D. (2009), Three lectures on post-industrial society, MIT Press. Cambridge, MA.

Collinson, D. (2003), "Identities and insecurities: Selves at work", Organization, Vol. 10 No. 3, pp. 527-547.

Costea, B., Amiridis, K. and Crump, N. (2012), "Graduate employability and the principle of potentiality: An aspect of the ethics of HRM", Journal of Business Ethics, Vol. 111 No. 1, pp. 25-36.

Coupland, C., Brown, A., Daniels, K. and Humphreys, M. (2008), "Saying it with feeling: Analysing speakable emotions", Human Relations, Vol. 61 No. 3, pp. 327353.

Courpasson, D. (2000), "Managerial Strategies of Domination: Power in Soft Bureaucracies", Organization Studies, Vol. 21 No. 1, pp. 141-61.

Crespo, E. and Serrano, A. (2011), "The Psychologisation of Work, The Deregulation of Work, and The Government of the Will", Annual Review of Critical Psychology, Vol. 8, pp. 43-61.

Delumeau, J. (1990), Sin and fear: The emergence of a western guilt culture, 13th-18th centuries, St. Martin's Press, New York.

Dean, M. (1995), "Governing the unemployed self in an active society", Economy and Society, Vol. 24 No. 4, pp. 559-583. 
de Jong, T., Wiezer, N., de Weerd, M., Nielsen, K., Mattila-Holappa, P. and Mockałło, Z. (2016), "The impact of restructuring on employee well-being: A systematic review of longitudinal studies", Work \& Stress, Vol. 30 No. 1, pp. 91-114.

Doherty, N. (1997), "The role of outplacement in redundancy management", Personnel Review, Vol. 27 No. 4, pp. 343-353.

Dostoyevsky, F. (1976), The brothers Karamazov, W.W. Norton \& Company, New York.

Drzensky, F. and Heinz, M. (2016), "The hidden costs of downsizing", The Economic Journal, Vol. 126 No. 598, pp. 2324-2341.

Elvin-Nowak, Y. (1999), "The meaning of guilt: A phenomenological description of employed mothers" experiences of guilt", Scandinavian Journal of Psychology, Vol. 40, pp. 73-83.

Fabricius, D. (2004), "Guilt, shame, disobedience: Social regulatory mechanisms and the "inner normative system"”, Psychoanalytic Inquiry, Vol. 24 No. 2, pp. 309-327.

Flynn, F. and Schaumberg, R. (2012), "When Feeling Bad Leads to Feeling Good: Guilt-Proneness and Affective Organizational Commitment", Journal of Applied Psychology, Vol. 97 No. 1, pp. 124-33.

Ford, J. and Collinson, D. (2011), "In search of the perfect manager? Work-life balance and managerial work", Work, Employment and Society, Vol. 25 No. 2, pp. 257-73.

Freud, S. (2003), Civilization and Its Discontents, Penguin Books, London.

Gandolfi, F. and Neck, P. (2007), "Causes, implementation, and processes of downsizing (A literature review of corporate downsizing: Part 2)", Revista de Management Comparat Internaţional, Vol. 8 No. 4, pp. 18-31.

Gandolfi, F. (2008), "Downsizing executioners and the experience of executing downsizing", The Journal of American Academy of Business, Vol. 13 No. 1, pp. 294302.

Gandolfi, F., and Hansson, M. (2011), "Causes and consequences of downsizing: Towards an integrative framework", Journal of Management \& Organization, Vol. 17 No. 4, pp. 498-521.

Gabriel, Y. (1997), "Meeting god: When organizational members come face to face with the organization's supreme leader", Human Relations, Vol. 50 No. 4, pp. 315342.

Garrety, K., Badham, R., Morrigan, V., Rifkin, W. and Zanko, M. (2003), "The use of personality typing in organizational change: Discourse, emotions and the reflexive subject", Human Relations, Vol. 56 No. 2, pp. 211-235.

Gilbert, J. (2000), "Sorrow and guilt: An ethical analysis of layoffs", SAM Advanced Management Journal, Vol. 65 No. 2, pp. 4-13.

Glover, L. (2010), "Can informal social relations help explain workers" reactions to managerial interventions? Some case evidence from a study of quality management", Economic and Industrial Democracy, Vol. 32 No. 3, pp. 357-378.

Gribble, L. and Miller, P. (2009), "Employees in outplacement services, do they really get the help they need", Australian Journal of Career Development, Vol. 18 No. 3, pp. 18-28.

Hallier, J. and Lyon, P. (1996), ““Job insecurity and employee commitment: Managers” reactions to the threat and outcomes of redundancy selection", British Journal of Management, Vol. 7 No. 1, pp. 107-123.

Harvey, D. (2007), A brief history of neoliberalism. Oxford: Oxford University Press. Henry, E. and Jennings, J. (2004), "Age discrimination in layoffs: Factors of injustice", Journal of Business Ethics, Vol. 54 No. 3, pp. 217-224. 
Hochwarter, W., Perrewé, P., Meurs, J. and Kacmar, C. (2007), "The interactive effects of work-induced guilt and ability to manage resources on job and life satisfaction", Journal of Occupational Health Psychology, Vol. 12 No. 2, pp. 125-135.

Hochschild, A. (1983), The managed heart: Commercialization of human feeling, University of California Press, London.

ILO (1997), "ILO highlights global challenge to trade unions", Press release 4 November 1997, International Labour Organization, Geneva. Available at: http://www.ilo.org/global/about-the-ilo/newsroom/news/WCMS_008032 (last accessed on 17/09/2018).

Isaksson, K., Hellgren, J., and Pettersson, P. (2005), "Union involvement during Downsizing and its Relation to Attitudes and Distress among Workers", in De Witte, H. (Ed.) Job Insecurity, Union Involvement and Union Activism, Routledge, London, pp. 97-116.

Jung, J. (2017), “A struggle on two fronts: labour resistance to changing lay off policies at large US companies", Socio-Economic Review, Vol. 15 No. 1, pp. 213-239.

Howard, C. (2007), "Introducing individualization", in Howard, C. (Ed.), Contested individualization: Debates about contemporary personhood, Palgrave MacMillan, New York, pp. 1-24.

Kafka, F. (2000), The trial, Penguin, London.

Kanfer, R. and Hulin, C. (1985) "Individual differences in successful job searches following lay-off”, Personnel Psychology, Vol. 38 No. 4, pp. 835-847.

Kawai, N. (2015), "Does downsizing really matter? Evidence from Japanese multinationals in the European manufacturing industry", The International Journal of Human Resource Management, Vol. 26 No. 4, pp. 501-519.

Kets De Vries, M. and Balazs, K. (1997), "The downside of downsizing”, Human Relations, Vol. 50 No. 1, pp. 11-50.

Knights, D. and Willmott, H. (2000), The Reengineering Revolution: Critical Studies of Corporate Change, Sage, London.

Kunda, G. (1992), Engineering culture: Control and commitment in a high-tech. corporation, Temple University Press, Philadelphia

Kuruvilla, S., Das, S., Kwon, H., and Kwon, S. (2002), "Union growth, decline and revitalization in Asia", British Journal of Industrial Relations, Vol. 40 No. 3, pp. 431461.

Lämsä, A.-M. and Takala, T. (2000), "Downsizing and ethics of personnel dismissals - The case of Finnish managers", Journal of Business Ethics, Vol. 23 No. 4, pp. 389399.

Lane, C. (2009), "Man enough to let my wife support me: How changing models of career and gender are reshaping the experience of unemployment", American Anthropologist, Vol. 36 No 4, pp. 681-692.

Lazonick, W. and O'Sullivan, M. (2000), "Maximizing shareholder value: A new ideology for corporate governance”, Economy and Society, Vol. 29 No. 1, pp. 13-35.

Levinas, E. (1969), Totality and infinity, Duquesne, Pittsburgh.

Li, Y., Ahlstrom, D. and Ashkanasy, N. (2010), "A multilevel model of affect and organizational commitment", Asia Pacific Journal of Management, Vol. 27 No. 2, pp. 193-213.

Lilley, S. (2010), "Introduction". In Lilley, S. (ed.) Capital and its discontents: Conversations with radical thinkers in a time of tumult. California: PM Press, pp. 123. 
Maglio, T. and Maas, J. (2018), "Viacom Begins Layoffs: Read CEO’s Internal Memo to Staff". Available at: https://www.thewrap.com/viacom-begins-another-round-oflayoffs/ (last accessed on 17/09/2018).

Marques, T., Galende, J., Cruz, P. and Ferreira, M. (2014), "Surviving downsizing and innovative behaviors: A matter of organizational commitment", International Journal of Manpower, Vol. 35 No. 7, pp. 930-955.

Martin, R. (2002), Financialization of daily life, Temple University Press, California.

McDevitt, R., Giapponi, C., and Houston, D. (2013), "Organizational downsizing during an economic crisis: Survivors' and victims' perspectives", Organization Management Journal, Vol. 10 No. 4, pp. 227-239.

Molinsky, A. and Margolis, J. (2005), "Necessary evils and interpersonal sensitivity in organizations", The Academy of Management Review, Vol. 30 No. 2, pp. 245-268.

Nietzsche, F. (2009), The genealogy of morals: A polemical tract, Richer Resources Publications, Virginia.

Noda, T. and Hirano, D. (2013), "Enterprise unions and downsizing in Japan before and after 1997", Journal of the Japanese and International Economies, Vol. 28, pp. 91-118.

Noer, D. (1993), Healing the wounds: Overcoming the trauma of layoffs and revitalizing downsized organizations, Jossey Brass, San Francisco.

Noer, D. (1995), "Center for creative leadership: Leadership in the age of layoffs", Journal of Management Development, Vol. 14 No. 5, pp. 27-38.

Noer, D. (2000), "Leading organizations through survivor sickness: a framework for the new millennium", in Burke, R. and Cooper, C. (Eds) The organization in crisis: Downsizing, restructuring, and privatization, Blackwell, Oxford, pp. 235-250.

Nolan, R. and Croson, D. (1995), Creative destruction: A six-stage process for transforming the organization, Harvard Business School Publishing, Boston.

Nowak, P. (2015), “The past and future of trade unionism", Employee Relations, Vol. 37 No. 6, 683-691.

Osthus, S. (2007), "For better or worse? Workplace changes and the health and wellbeing of Norwegian workers", Work, Employment and Society, Vol. 21 No. 4, pp. 731-750.

Paul, K. and Moser, K. (2009), "Unemployment impairs mental-health: metaanalyses", Journal of Vocational Behavior, Vol. 74 No. 3, pp. 264-282.

Picot, G., Lin, Z. and Pyper, W. (1998), "Permanent layoffs in Canada: Overview and longitudinal analysis", Canadian Journal of Economics, Vol. 31 No. 5, pp. 11541178.

Reinardy, S. (2010), "Downsizing effects on personnel: The case of layoff survivors in U.S. newspapers", Journal of Media Business Studies, Vol. 7 No. 4, pp. 1-19.

Rodrigues, S. and Collinson, D. (1995), “Having fun'?: Humor as resistance in Brazil”, Organization Studies, Vol. 16 No. 5, pp. 739-768.

Rose, N. (1999), Power of freedom: Reframing political thought, Cambridge University Press, Cambridge.

Rosenblatt, Z. and Schaeffer, Z. (2000), "Ethical problems in downsizing", in Burke, $\mathrm{R}$. and Cooper, C. (Eds) The organization in crisis: Downsizing, restructuring and privatization, Blackwell Business, Oxford, pp. 132-150.

Sennett, R. (1998), The corrosion of character: The personal consequences of work in the new capitalism, Norton, New York.

Scheff, T. (1994), Bloody revenge: Nationalism, war, and emotion, Westview, Boulder. Schenkel, A. and Teigland, R. (2017), "Why doesn't downsizing deliver? A multi-level model integrating downsizing, social capital, dynamic capabilities, and firm 
performance", The International Journal of Human Resource Management, Vol. 28 No. 7, pp. 1065-1107.

Shakespeare, W. (1992), Macbeth, Wordsworth, London.

Stanford Rose Associates (2018), "Candidates". Available at: $\mathrm{http}: / /$ sanfordrose.com/ziemsgroup/candidate-resources/ (last accessed on 25/01/2018)

Sharone, O. (2007), "Constructing unemployed job seekers as professional workers: The depoliticizing work-game of job searching", Qualitative Sociology, Vol. 30 No. 4, pp. 403-416.

Sharone, O. (2013), "Why do unemployed Americans blame themselves while Israelis blame the system", Social Forces, Vol. 91 No. 4, pp. 1429-1450.

Shouse, E. (2005), "Feeling, emotion, affect", M/C Journal, Vol. 8 No. 6, available at: http:journal.media-culture.org.au (last accessed on 9/2/2018).

Siemiatycki, E. (2012), "Forced to concede: Permanent restructuring and labours place in the North American auto industry", Antipode, Vol. 44 No. 2, pp. 453-473.

Simonetti, J., Nykodym, N., Nielsen, W. and Goralske, J. (1993), "Counselling employee guilt: A corporate necessity”, Employee Counselling Today, Vol. 5 No. 3, pp. 17-23.

Silver, S., Shields, J., Wilson, S., and Scholtz, A. (2009), "The excluded, the vulnerable and the reintegrated in a neoliberal era: Qualitative dimensions of the unemployment experience", Socialist Studies, Vol. 1 No. 1, pp. 31-56.

Smith, L. (1994), "Burned-out bosses", Fortune, 130, pp. 44-52.

Snorradottir, A., Tomasson, K., Vilhjalmsson, R. and Rafnsdottir, G. (2015), "The health and well-being of bankers following downsizing: A comparison of stayers and leavers", Work, Employment and Society, Vol. 29 No. 5, pp. 738-756.

Spicer, A. (2011), "Guilty lives: The authenticity trap at work", Ephemera: Theory and Politics in Organizations, Vol. 11 No. 1, pp. 46-62.

Streek, W. (2011), "The crises of democratic capitalism", New Left Review, Vol. 71, pp. 5-29.

Swisher, K. (2009), "Steve Ballmer's Entire Memo to the Microsoft troops about layoffs and weak results". Available at: http:/allthingsd.com/20090122/steveballmers-entire-memo-to-the-microsoft-troops-about-layoffs-and-weak-results/ (last accessed on 09/02/2018).

The company men. Directed by John Wells. The Weinstein Company, 2010.

Tomasko, R. (1991), "Downsizing, layoffs and alternatives to layoffs", Compensation and Benefits Review, Vol. 23 No. 4, pp. 19-32.

Travaglione, A. and Cross, B. (2006), "Diminishing the social network in organizations: does there need to be such an organizational phenomenon as 'survivor syndrome' after downsizing", Strategic Change, Vol. 15, pp. 1-13.

Trevor, C. and Nyberg, A. (2008), "Keeping your headcount when all about you others are losing theirs: downsizing, voluntary turnover, and the moderating role of HR practices", Academy of Management Journal, Vol. 51 No. 2, pp. 259-276.

Turnbull, P. (2001), "Leaner and possibly fitter: The management of redundancy in Britain", Industrial Relations Journal, Vol. 19 No. 3, pp. 201-213.

Tyrrell, M. (1994, April), “"Its not your fault, but...”: Notes on the ritualization of corporate culture change in firing practices". Paper presented at the annual meeting of the North Eastern Anthropology Association, Geneseo, NY.

Uchitelle, L. (2007), The disposable Americans: Layoffs and their consequences, Vintage, New York.

Up in the air. Directed by Jason Reitman. Paramount Pictures, 2009. 
Van Dick, R., Drzensky, F. and Heinz, M. (2016), "Goodbye or identify: Detrimental effects of downsizing on identification and survivor performance", Frontiers in Psychology, Vol. 7, 771.

Wager, T. (1998), "Exploring the consequences of workforce reduction", Canadian Journal of Administrative Sciences, Vol. 15 No. 4, pp. 300-309.

Warnick, Q. (2010), "A close textual analysis of corporate layoff memos", Business Communication Quarterly, Vol. 73 No. 3, pp. 322-326.

Weber, M. (1992), The protestant ethic and the spirit of capitalism, Routledge, London.

Wiesenfeld, B., Brockner, J. and Martin. C. (1999), "A self-affirmation analysis of survivors" reactions to unfair organizational downsizings", Journal of Experimental Social Psychology, Vol. 35 No. 5, pp. 441-460.

Worrall, L., Cooper, C. and Campbell, F. (2000), "The new reality for UK managers: Perpetual change and employment instability", Work, Employment and Society, Vol. 14 No. 4, pp. 647-668.

\section{Appendices}

\section{Appendix A - Corporate Memo Microsoft, \\ Source: http://allthingsd.com/20090122/steve-ballmers-entire-memo-to-the-microsoft- troops-about-layoffs-and-weak-results/}

From: Steve Ballmer

To: All Microsoft FTE

Subject: Realigning Resources and Reducing Costs

In response to the realities of a deteriorating economy, we're taking important steps to realign Microsoft's business. I want to tell you about what we're doing and why.

Today we announced second quarter revenue of $\$ 16.6$ billion. This number is an increase of just 2 percent compared with the second quarter of last year and it is approximately $\$ 900$ million below our earlier expectations.

The fact that we are growing at all during the worst recession in two generations reflects our strong business fundamentals and is a testament to your hard work. Our products provide great value to our customers. Our financial position is solid. We have made long-term investments that continue to pay off. But it is also clear that we are not immune to the effects of the economy. Consumers and businesses have reined in spending, which is affecting PC shipments and IT expenditures.

Our response to this environment must combine a commitment to long-term investments in innovation with prompt action to reduce our costs.

During the second quarter we started down the right path. As the economy deteriorated, we acted quickly. As a result, we reduced operating expenses during the quarter by $\$ 600$ million. I appreciate the agility you have shown in enabling us to achieve this result.

Now we need to do more. We must make adjustments to ensure that our investments are tightly aligned with current and future revenue opportunities. The current environment requires that we continue to increase our efficiency.

As part of the process of adjustments, we will eliminate up to 5,000 positions in R\&D, marketing, sales, finance, LCA, HR, and IT over the next 18 months, of which 1,400 will occur today. We'll also open new positions to support key investment areas during this same period of time. Our net headcount in these functions will decline by 2,000 to 3,000 over the next 18 months. In addition, our workforce in support, consulting, operations, billing, manufacturing, and data center operations will continue to change in direct response to customer needs.

Our leaders all have specific goals to manage costs prudently and thoughtfully. They have the flexibility to adjust the size of their teams so they are appropriately matched to revenue potential, to add headcount where they need to increase investments in order to ensure future success, and to drive efficiency.

To increase efficiency, we're taking a series of aggressive steps. We'll cut travel expenditures 20 percent and make significant reductions in spending on vendors and contingent staff. We've scaled back Puget Sound campus expansion and reduced marketing budgets. We'll also reduce costs by eliminating merit increases for FY10 that would have taken effect in September of this calendar year. 
Each of these steps will be difficult. Our priority remains doing right by our customers and our employees. For employees who are directly affected, I know this will be a difficult time for you and I want to assure you that we will provide help and support during this transition. We have established an outplacement center in the Puget Sound region and we'll provide outplacement services in many other locations to help you find new jobs. Some of you may find jobs internally. For those who don't, we will also offer severance pay and other benefits.

The decision to eliminate jobs is a very difficult one. Our people are the foundation of everything we have achieved and we place the highest value on the commitment and hard work that you have dedicated to building this company. But we believe these job eliminations are crucial to our ability to adjust the company's cost structure so that we have the resources to drive future profitable growth.

I encourage you to attend tomorrow's Town Hall at 9am PST in Café 34 or watch the webcast.

While this is the most challenging economic climate we have ever faced, I want to reiterate my confidence in the strength of our competitive position and soundness of our approach.

With these changes in place, I feel confident that we will have the resources we need to continue to invest in long-term computing trends that offer the greatest opportunity to deliver value to our customers and shareholders, benefit to society, and growth for Microsoft.

With our approach to investing for the long term and managing our expenses, I know Microsoft will emerge an even stronger industry leader than it is today.

Thank you for your continued commitment and hard work.

Steve

\section{Appendix B: Corporate Memo Yahoo. Source: https://techcrunch.com/2008/10/21/jerry- yang-email-to-all-yahooers/}

From: Jerry Yang [mailto:jerry@yahoo-inc.com]

Sent: Tuesday, October 21, 2008 2:20 PM

To: all-worldwide@yahoo-inc.com

Subject: update

yahoos,

i feel it's important for me to reach out to you after our earnings announcement, and before our all hands meeting tomorrow.

we as a company have been through a tremendously challenging year; and managing the increasingly turbulent global advertising climate has been an important focus for the last three months.

throughout the first three quarters of 2008, we have been balancing between investing in our top priorities, and managing our cost structure. beginning in september, with the help of Bain \& Co., we initiated a series of steps to determine how we can become more efficient and productive as an organization.

we heard from you through the YEES survey, and through your suggestions on backyard, and we've identified many areas that we all feel we can improve upon. our productivity efforts, based in part on what we heard from you, will involve initiatives such as streamlining our organizational structure through reducing layers and increasing spans of control, and eliminating redundancies. longer term structural efficiencies include consolidating facilities, improving procurement, and standardizing our global technology platforms.

today as part of our q3 earnings release, we said that our goal is to reduce our current annualized cost run rate of roughly $\$ 3.9$ billion by more than $\$ 400$ million before the end of 2008 . we are targeting nonheadcount expenses wherever possible, such as facilities and outside services. however, because compensation expenses are the single largest part of our costs, we anticipate a reduction of at least $10 \%$ of our global workforce by year-end.

affected employees will be notified of layoffs in the next several weeks. we understand that hearing this news now creates uncertainty, but we are moving ahead in a way that balances speed with a clear focus on accomplishing what is necessary to set the organization up for long term success. going forward it will continue to be important for us to make the right decisions to keep our business efficient and strong. having layoffs is very difficult, particularly in light of all we've experienced this year. but we don't take these decisions lightly, and are committed to treating affected employees fairly, offering severance and outplacement services.

the steps we are taking are not easy for us as a company, but as we become more fit as an organization, decision-making will be faster and it will be easier for us all to get more done and stay focused on our strategy. these changes will also prepare us to better deal with the macroeconomic downturn. as with previous downturns, yahoo! continues to be a place where consumers turn for information and 
communications, and is an integral part of their internet day. as the global economy improves in the future, i certainly believe that we will be stronger and benefit from the actions we are taking now. as always, $\mathrm{i}$ thank you for all you do as yahoos.

best,

jerry

Appendix C: Corporate Memo Times Inc., Source: http://allthingsd.com/20081028/theentire-time-inc-layoff-memo-from-ann-moorel

From: Moore, Ann - Executive Administration

Sent: Tue Oct 28 18:00:37 2008

Subject: Staff Announcement

October 28, 2008

To: Time Inc. Employees

From: Ann Moore

Re: Staff Announcement

As all of you are aware, industry conditions have been challenging due to the financial crisis, which has produced sharp decreases in advertising spending. This is expected to continue through most of 2009. It's important that we at Time Inc. react quickly to this new reality in order to maintain our financial strength, build our market position, and sharpen our ability to bounce back at the first signs of economic recovery. All the while we must continue to give our readers and audience the high quality editorial products they have come to expect from our publications and websites.

This is a challenge, unlike any we've seen before. And after much careful study and consultation with many of you who run our businesses, I have concluded that it is no longer possible to operate our company with the same decentralized management structure that served us so well during our many years of sustained growth.

So, effective tomorrow, we are going to implement a much more centralized management structure, organized into three business units that will group together titles that share similar audiences, advertisers, and the talents and skills of their staffs. The goal is to enable our company to move faster, go to market smarter, save significant costs, and employ our editorial resources more efficiently.

In broad strokes, here is how it will work:

Business Units. Time Inc.'s 24 U.S. magazines and companion web sites will be grouped into three business units, each reporting to a senior corporate executive. Each unit will have a similar structure that will include four key executives to direct the ad sales, digital business, financial and editorial efforts across that group. One of the most significant centralizing features of this new structure is that each of the three units will have one General Manager, responsible for all budgeting in the unit, who will report directly to Time Inc. EVP and CFO Howard Averill, with a dotted line to their respective senior operating executive.

The three Business Units will consist of:

* News: the existing print and digital properties in the TIME group, the Fortune|Money group, and the Sports Illustrated group, as well as Life.com and GEE. John Squires, EVP Time Inc. will manage the News Business Unit.

* Style and Entertainment: the existing print and digital properties in the PEOPLE group, InStyle, Entertainment Weekly, and Essence. I will act as the EVP for this group so the Style and Entertainment Business Unit will report to me.

* Lifestyle: the existing print and digital properties of Real Simple, This Old House, All You, Southern Living, Cooking Light, Sunset, Health, Cottage Living, Coastal Living, and Southern Accents, along with MyRecipes.com and MyHomeIdeas.com. Sylvia Auton, EVP Time Inc. will manage the Lifestyle Business Unit, while also retaining responsibility for IPC Media.

Editorial. John Huey continues as Time Inc.'s Editor-in-Chief, overseeing the News Business Unit Managing Editors and Martha Nelson, the Managing Editor of the Style and Entertainment Business Unit. In editorial alone we have seen three recent examples of how this sharing across titles can work to our benefit. During the summer Olympics, Sports Illustrated set up a system to supply Time.com with a fantastic array of photos from the games; in Europe and Asia, FORTUNE and TIME already are sharing correspondents; and, of course, the most visible example was the recent TIME cover story on the economy written by FORTUNE managing editor Andy Serwer and Allan Sloan. In the new structure we will see much more of this kind of cooperation. 
Time Inc. Advertising Sales and Marketing. Given the difficult ad sales environment, it is critical that all of our brands work together to efficiently and effectively offer advertisers the solutions they need. For this reason, we are creating Time Inc. Advertising Sales and Marketing, a group that will be charged with setting and executing corporate ad sales strategy along with the ad sales head for each business unit. Stephanie George will become President of Time Inc. Advertising Sales and Marketing and will remain a Time Inc. EVP. She will also remain on the Board of American Express Publishing.

Time Inc. Consumer Marketing and Sales. Consumer Marketing and Sales will be run by Brian Wolfe, who has been promoted to EVP and will report directly to me. All Consumer Marketing and Sales activities will be centralized under Brian. This department will be responsible for circulation net income across all U.S. Magazines, as well as Synapse, QSP, Time Warner Retail, Time Customer Service, and TW4, Time Inc.'s international fulfillment operation.

Everyone in the Consumer Marketing organization should be proud of their accomplishments in this difficult environment-some of our largest newsstand titles are having record years and we are seeing strong circulation net income results across the company. These organizational changes, along with the recent acquisition of QSP and the incorporation of Synapse into Time Inc. Consumer Marketing and Sales, will give Brian and his team the ability to continue this momentum by making the best decisions for the company as a whole, and making them quickly and definitively.

Finally, I'm pleased to announce the promotions of Kerry Bessey and Maurice Edelson to EVP, Time Inc.

Time Inc. Senior Management along with the Business Unit leaders are working on restructuring within each group, and will announce further changes in the coming weeks. While the broader economy and the advertising industry both continue to present challenges, I know we can weather this storm and emerge as an even stronger company when the economy begins to recover. We are still a very profitable company. Our cash flow is strong. We have made tremendous progress with our digital business. Each month, more than 26 million people visit Time Inc. websites. We know our consumers continue to value our magazines and websites. We have the top brands in all the categories where we publish and we're finding exciting new ways to expand our titles beyond the printed page and the web. The importance of fact-based journalism has never been clearer given the many serious issues facing the world and our core competency, trusted editing skills, has never been more needed than in this time of too much information. I'd like to thank you all for your continued hard work.

A.M.

\section{Appendix D: Corporate Memo Twitter, Source: http://uk.businessinsider.com/jack- dorseys-layoff-letter-to-twitters-staff-2015-10}

From: Jack Dorsey

To: All Employees

Date: October 13, 2015

Subject: A more focused Twitter

Team,

We are moving forward with a restructuring of our workforce so we can put our company on a stronger path to grow. Emails like this are usually riddled with corporate speak so I'm going to give it to you straight.

The team has been working around the clock to produce streamlined roadmap for Twitter, Vine, and Periscope and they are shaping up to be strong. The roadmap is focused on the experiences which will have the greatest impact. We launched the first of these experiences last week with Moments, a great beginning, and a bold peek into the future of how people will see what's going on in the world.

The roadmap is also a plan to change how we work, and what we need to do that work. Product and Engineering are going to make the most significant structural changes to reflect our plan ahead. We feel strongly that Engineering will move much faster with a smaller and nimbler team, while remaining the biggest percentage of our workforce. And the rest of the organization will be streamlined in parallel.

So we have made an extremely tough decision: we plan to part ways with up to 336 people from across the company. We are doing this with the utmost respect for each and every person. Twitter will go to great lengths to take care of each individual by providing generous exit packages and help finding a new job.

Let's take this time to express our gratitude to all of those who are leaving us. We will honor them by doing our best to serve all the people that use Twitter. We do so with a more purpose-built team, which we'll continue to build strength into over time, as we are now enabled to reinvest in our most impactful priorities. 
Thank you all for your trust and understanding here. This isn't easy. But it is right. The world needs a strong Twitter, and this is another step to get there. As always, please reach out to me directly with any ideas or questions.

Jack

Appendix E: Corporate Memo Viacom, Source: https://www.thewrap.com/viacombegins-another-round-of-layoffs/

From: Bob Bakish

To: Staff (Internal Memo)

Date: February 06, 2018

Team,

I know there's been a lot of news in the past week - over the last year, in fact - about change (or potential change) in this company. I think it's important to remember that so much of this change, while not always easy, has made us stronger. We've brought in new talent, re-energized our brands, rebuilt relationships - both inside these walls and out - and taken many other steps to strengthen and evolve our company for the future.

And, yes, sometimes change means making tough decisions - like today, where we made some changes across the organization. While these changes didn't impact a large percentage of our workforce, I know they were difficult nonetheless. We are saying goodbye to some great team members, some of whom have been here for a long time, and have made an important impact on this organization. We're so grateful for their contributions, and want to assure you we're taking many steps to make their transitions easier. It's also very important to understand how purposeful our changes have been. It isn't just about cutting costs - although we want savings, too, and more flexibility to invest in new areas. These moves are really about our continued efforts to create a more agile and efficient organization that can thrive in a time of constant change. I'll be giving you more context around all of this in our Bob Live on Thursday, and can take any questions you have.

I'm so proud of all we've accomplished over the past year, and couldn't be more excited about the opportunity the change in our industry creates. I want us to be an organization that is energized by reinventing this business, and has the capability and capacity to constantly transform. Let's continually push ourselves to discover what's new, and what's next. Let's get out of our silos and learn from each other, and create the new faster. Let's embrace change and possibility.

Thank you for supporting each other through this process, and for your continued focus in driving us forward.

Best,

Bob

Appendix F: Termination Script, Source: Tyrell, M. (1994)

\section{The News}

"John, I am afraid that I have bad news for you today. It is with regret that I must advise you that, as a result of the reorganization and changes in the department, your employment will cease effective today, May 10th, 1990."

\subsection{The Support}

[Quickly summarize the contents of the termination letter (avoid having the employee read the letter in you presence)]

"What I would like to do now is to review with you the details of your termination package. The company is prepared to offer you a separation package which includes statutory requirements, plus a severance for a total of ......., etc." "The company has retained, at our own expense, the firm of Work transitions Canada to help you in your job search. While it is entirely up to you, I would encourage you to take full advantage of their services and programs to help you find other employment."

[Give the employee his/her envelope]

\subsection{The Close}

"I am really sorry I had to tell you this, John. I know you are going to have a lot of questions and that is quite understandable. I will be available to discuss them 
with you later today, tomorrow and through the next few weeks. However, because I have a number of people to speak with, let me take you and introduce you to , of the consulting firm."

[Ensure that the employee has a contact name in human resources for questions]

"You probably have a number of personal effects to take home from your office. If you would rather do this later, let me know and I will arrange a time for you to return. John, there is not much more that I can say, except that I have enjoyed working with you and I would like to take this opportunity to personally thank you for your commitment and loyalty. It goes without saying, if I can be of help, let me know."

[Escort the employee to the consultant, introduce them and shake the employee's hand as you leave.] 